\title{
The effects of subchronic exposure to ketoprofen on early developmental stages of common carp
}

\author{
Eva Prášková ${ }^{1}$, Stanislava Štěpánová ${ }^{1}$, Lucie Chromcová ${ }^{1}$, Lucie Plhalová1, \\ Eva Voslářová1, Vladimíra Pištěková ${ }^{\text {, Miroslav Prokeš² }}{ }^{2}$ Zdeňka Svobodová ${ }^{1}$ \\ ${ }^{1}$ University of Veterinary and Pharmaceutical Sciences, Faculty of Veterinary Hygiene and Ecology, \\ Department of Veterinary Public Health and Toxicology, Brno, Czech Republic \\ ${ }^{2}$ Institute of Vertebrate Biology, Academy of Sciences of the Czech Republic, v.v.i., Brno, Czech Republic
}

Received January 18, 2013

Accepted June 19, 2013

\begin{abstract}
Ketoprofen residues have been found in surface water where they present a potential risk to nontarget aquatic species. The aim of this study was to assess the impact of ketoprofen in surface waters on fish under experimental conditions. Subchronic toxic effects on 300 embryos and larvae of common carp (Cyprinus carpio) were investigated during a 30 day toxicity test with concentrations of ketoprofen: $0.003,2.1,6.3$ and $21 \mathrm{mg} / \mathrm{l}$. The exposure to ketoprofen showed no effect on mortality, but we observed significant delay $(P<0.05)$ in hatching in day 3 in fish exposed to all concentrations of ketoprofen. Significant delays $(P<0.05)$ in development were revealed at 2.1, 6.3 and $21 \mathrm{mg} / 1$ ketoprofen. On the basis of weight and growth rate evaluation and the determination of developmental stages, the lowest observed effect concentration was $0.003 \mathrm{mg} / \mathrm{l}$. According to these results, the reported environmental concentration of ketoprofen in Czech rivers could have a negative effect on the growth and development of carp embryos and larvae. These tests have not yet been performed. Further research and search for a mechanism to reduce the incidence of ketoprofen in the waters by better wastewater treatment is required.
\end{abstract}

\section{Embryo-larval toxicity test, NSAIDs, environmental concentration}

Use of pharmaceuticals for human and veterinary medicine leads to the excretion of unchanged drugs and their metabolites into urban wastewaters, which together with the improper disposal of unused and expired drugs leads to considerable concentrations of various pharmaceuticals in municipal sewage. Discharge from sewage treatment plants is one of the main sources of pharmaceuticals in the aquatic environment (Fent et al. 2006; Thibaut et al. 2006).

Non-steroidal anti-inflammatory drugs (NSAIDs), such as diclofenac, ketoprofen and ibuprofen are human pharmaceuticals that are frequently detected in surface waters, municipal wastewaters and drinking waters almost worldwide at concentrations in $\mathrm{ng} / \mathrm{l}$ to $\mu \mathrm{g} / \mathrm{l}$ (Kolpin et al. 2002; Corcoran et al. 2010; Kodes et al. 2010). The therapeutic role of these pharmaceuticals is to reduce inflammation and pain. The mechanism of the effect of non-steroidal anti-inflammatory drugs is the inhibition of cyclooxygenases, enzymes that catalyse the synthesis of prostaglandins via the oxidation of arachidonic acid (Vane and Botting 1998).

Pharmaceuticals are generally designed to have low toxicity but there is the potential for unintended side effects. Although various cases of the detection of pharmaceuticals in water are described in the literature, the complete impact of ketoprofen on non-target organisms has not been described yet. There is no relevant information on its mechanism of action and the consequences of exposure in aquatic organisms. We used common carp (Cyprinus carpio) as the test organism.

The aim of this study was to assess the effects of subchronic exposure to sublethal concentrations of ketoprofen in embryo-larval developmental stages of common carp. The lowest tested concentration was corresponding to environmental concentrations and

Address for correspondence:

Eva Prášková

Department of Veterinary Public Health and Toxicology

Faculty of Veterinary Hygiene and Ecology

University of Veterinary and Pharmaceutical Sciences in Brno

Palackého tř. 1/3, 61242 Brno, Czech Republic 
the highest tested concentration was approximately $1000 \times$ higher. The presumption was that ketoprofen at higher concentration would influence growth and development of fish whereas environmental concentration of ketoprofen would affect histological findings.

\section{Experimental protocol}

\section{Materials and Methods}

Embryo-larval toxicity tests were performed with ketoprofen (CAS 22071-15-4, Sigma-Aldrich, Czech Republic). Ketoprofen has low solubility $(240 \mathrm{mg} / \mathrm{l})$ in water. For better mixing and dissolution of the substance we used an ultrasoud device. Toxicity tests were carried out using a modified protocol according to OECD guideline 210 (Fish, Early-life stage toxicity test, OECD 1992). Experimental procedures were in compliance with the national legislation (Act No. 246/1992 Coll., on the protection of animals against cruelty, as amended and decree No. 207/2004 Coll., on the protection, breeding and use of experimental animals, as amended).

Fertilized eggs of common carp were obtained from a commercial fish farm. Eggs were produced according to standard methods of artificial reproduction as described by Koc our et al. (2005). Twenty-four hours post-fertilization, 300 fertilized eggs were separated from unfertilized eggs and randomly distributed into fifteen crystallization dishes containing one of four ascending concentrations of ketoprofen solution, or into a control dish (ketoprofenfree tap water). The experiment was conducted in triplicate. Tested concentrations were selected according to the environmental concentration, with the lowest tested concentration corresponding to the environmental concentration. Due to lack of preliminary data on the effects of ketoprofen on fish, a wide range of concentrations was tested, i.e. $0 \mathrm{mg} / \mathrm{l}$ (control), $0.003 \mathrm{mg} / \mathrm{l}$ (environmental concentration mentioned by Kodes et al. 2010), 2.1, $6.3 \mathrm{and} 21 \mathrm{mg} / \mathrm{l}$. Concentrations during the test did not sink below $80 \%$ of the nominal concentration. The water temperature was $22 \pm 1.5^{\circ} \mathrm{C}$; $\mathrm{pH}$ was between 7.5 and 8.5 , and dissolved oxygen did not fall below $60 \%$. A semi-static method was used in which the testing solution was replaced twice daily. Hatching and survival were also observed twice a day, and dead embryos and larvae were removed. During the test, larvae were fed ad libitum freshly-hatched Artemia salina twice a day prior to the bath exchange. The temperature, $\mathrm{pH}$, and oxygen saturation were recorded daily. The beginning of the test was designated Day 1 (one day post-fertilization). Hatching began on Day 3 and was completed by day 5 . Feeding with $A$. salina was initiated on Day 6 . The test was concluded on Day 30, when all of the larvae in the control groups reached the juvenile stage.

During the test, embryos and larvae were sampled to record developmental stage, length, weight, Fulton's condition factor (FCF), length-weight relationship, and morphological anomalies. Samples from each concentration and from the control were collected on days $6,10,15,20,24$ and at the completion of the test on Day 30. Fish were fixed in $4 \%$ formalin.

Determination of developmental stages

The developmental stages were determined according to Penaz et al. (1983), who described nine embryonic (E1-E9), six larval (L1-L6), and two juvenile (J1-J2) stages in common carp. Total length (TL) was measured stereomicroscopically using a micrometer to $0.01 \mathrm{~mm}$; weight $(\mathrm{W})$ was measured to $0.1 \mathrm{mg}$.

Weight and growth rate evaluation

Fulton's condition factor was calculated at each sampling time.

$\mathrm{FCF}=\frac{\mathrm{W} \cdot 10^{5}}{\mathrm{~L}^{3}}$

(W - weight in $\mathrm{g}, \mathrm{L}$ - total length in $\mathrm{mm}$ )

The mean specific growth rate (SGR) was calculated for each experimental group on Day 6 (the first sampling time) and on completion of the test on Day 30.

$\mathrm{SGR}=\frac{\overline{\mathrm{Inw}_{2}}-\overline{\mathrm{Inw}_{1}}}{\mathrm{t}_{2}-\mathrm{t}_{1}} \cdot 100$

(SGR - specific growth rate, $\mathrm{w}_{1}$ - weight of one fish at time $\mathrm{t}_{1}, \mathrm{w}_{2}$ - weight of one fish at time $\mathrm{t}_{2}, \mathrm{t}_{1}$ - first sampling time, $\mathrm{t}_{2}$ - end of the test)

The inhibition of specific growth rate (I) for each experimental group was calculated as follows:

$\mathrm{I}[\%]=\frac{\mathrm{SGR}(\text { control })-\mathrm{SGR}(\text { group })}{\mathrm{SGR}(\text { control })} \cdot 100$

Histopathological examination

The fish were prepared for histopathological examination, fixed in buffered $10 \%$ neutral formalin, dehydrated, embedded in paraffin wax, sectioned (cross section) on a microtome at $4 \mu \mathrm{m}$, and stained with haematoxylin and eosin (H\&E). The histology of skin, gill, kidneys and liver was examined by light microscopy. 
Statistical analysis

Results were analyzed using STATISTICA 8.0 for Windows (StatSoft, CR). After testing for normality of all variables (Kolmogorov-Smirnov test) and the homogenity of variances across groups (Levene test), data were subjected to parametric ANOVA - Tukey's HSD test (Zar 1996). Data of hatching were tested using contingency table analysis.

\section{Results}

Hatching and cumulative mortality

Eggs began to hatch on Day 3. The majority of the eggs hatched by Day 4; hatching was completed by Day 5. Significant delays $(P<0.05)$ in hatching were observed on Day 3 in fish exposed to all concentrations of ketoprofen. No significant $(P>0.05)$ differences were found in total cumulative mortality among groups. In all experimental and control groups, mortality was below $10 \%$.

\section{Total length and weight indices}

Increases in the total body length $(\mathrm{mm})$ and weight $(\mathrm{mg})$ of embryos and larvae over time in relation to ketoprofen concentration in water are depicted in Figs 1 and 2. The influence of ketoprofen concentration on the body weight and body length of carp larvae began to be evident from Day 6.

The influence of ketoprofen on FCF was not significant $(P>0.05)$. The mean FCF value at the end of the test was 1.47 in control and 1.40, 1.38, 1.38 and 1.39 in the tested concentrations $0.003,2.1,6.3$, and $21 \mathrm{mg} / 1$, respectively. The inhibition of specific growth rate was $11 \%$ at the ketoprofen concentration of $21 \mathrm{mg} / \mathrm{l}$, which was the highest value compared to the control group.

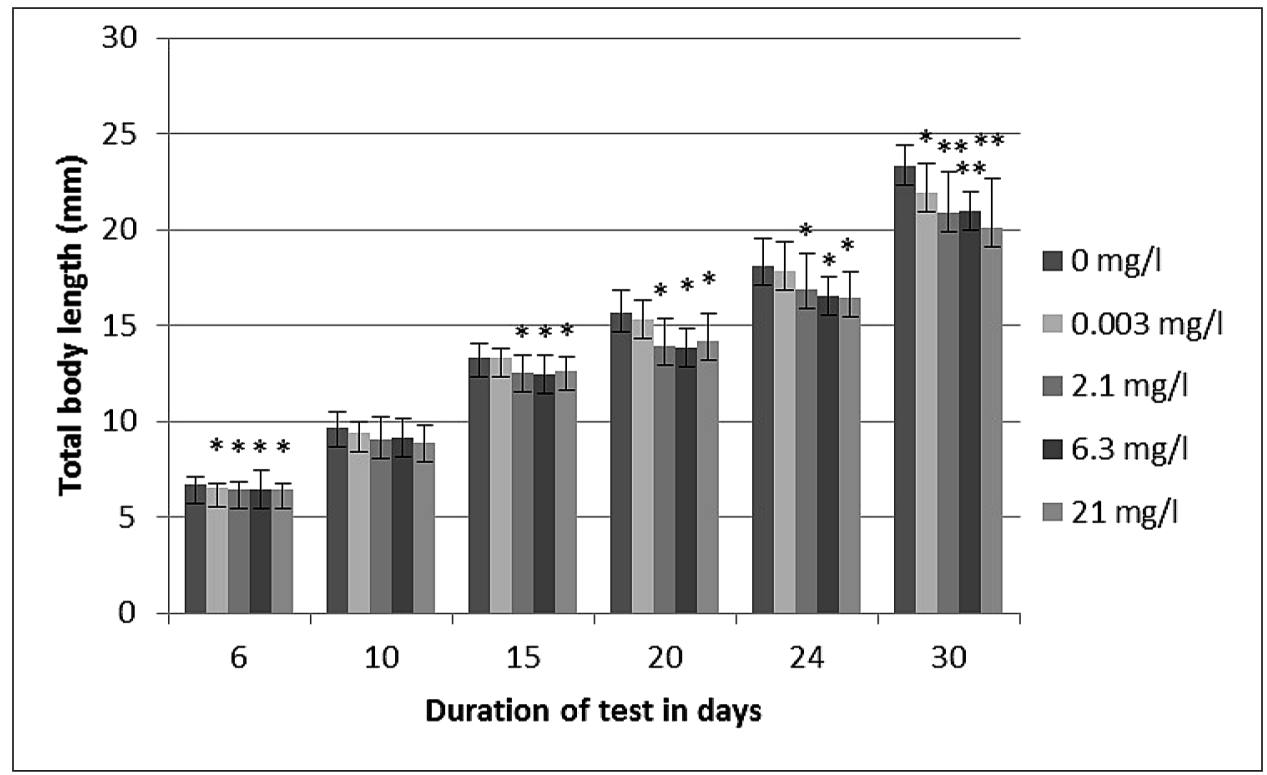

Fig. 1. Total body length (mean $\pm \mathrm{SD}$ ) of common carp during the embryo-larval toxicity test of ketoprofen.

$* P<0.05 ; * * P<0.01$ 


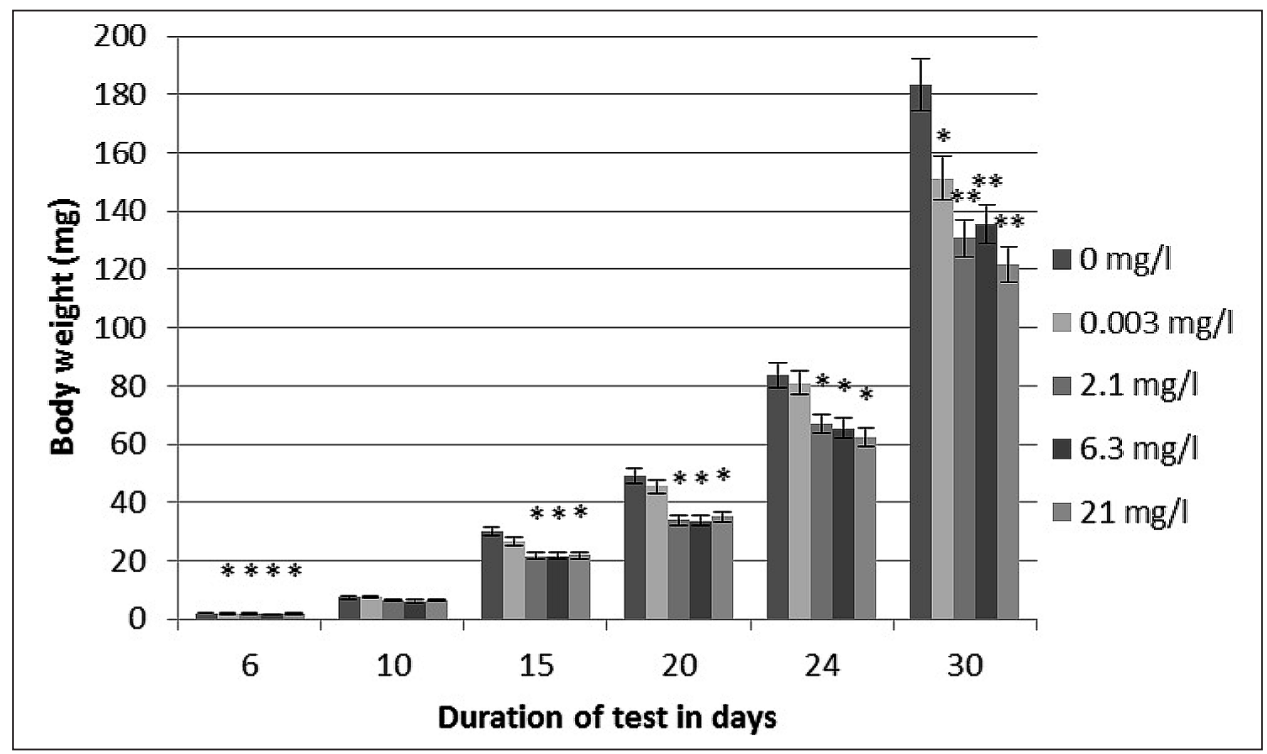

Fig. 2. Body weight (mean $\pm \mathrm{SD}$ ) of common carp during the embryo-larval toxicity test of ketoprofen.

$* P<0.05 ; * * P<0.01$

Early ontogeny, morphological anomalies and histopathology

Developmental stages were recorded at each sampling time in all groups. Differences in early ontogeny between control and experimental groups were evident at the completion of the test. At the end of the test, fish from groups treated with 2.1, 6.3 and $21 \mathrm{mg} / \mathrm{l}$ ketoprofen were delayed in development $(P<0.05)$ in a dose-dependent manner compared to the control group. After 30 days, all fish in the control group reached the juvenile stage (J1). At the ketoprofen concentration of $0.003 \mathrm{mg} / \mathrm{l}$, the rate was $100 \%$, but at $2.1,6.3$ and $21 \mathrm{mg} / \mathrm{l}$ it was $76 \%, 77 \%$ and $71 \%$, respectively.

No significant morphological anomalies or histological changes in samples of skin, liver, kidneys and gills were found.

Based on examination of the growth indices and development of all replications, the Lowest Observed Effect Concentration (LOEC) was determined to be $0.003 \mathrm{mg} / \mathrm{l}$.

\section{Discussion}

In this study, we examined the subchronic effect of exposure of common carp to ketoprofen. During the 30-day exposure of embryo-larval developmental stages of carp to low concentrations of ketoprofen $(0.003,2.1,6.3$, and $21 \mathrm{mg} / \mathrm{l})$ no influence on the mortality of the exposed groups compared to controls were found. However, ketoprofen exposure was observed to have an effect on the development of total length and body weight. Retardation of growth in the experimental groups when compared to the control group became evident on Day 6. After 30 days of exposure to ketoprofen, significantly smaller fish were found in all tested concentrations in comparison to the control fish.

Ketoprofen did not induce morphological anomalies during the experiment, but a delay in the early development of carp was evident. After 30 days of exposure, all fish in the control group and most fish in the experimental groups reached the juvenile stage. Studies 
performed on early developmental stages of fish confirmed that NSAIDs (ketoprofen and diclofenac) should have an effect on hatching, displaying signs of hydroedema (Hallare et al. 2004; Praskova et al. 2011). Van den Brandhof and Montforts (2010) found growth retardation, delayed hatching, and yolk sac and tail deformation in zebrafish embryos exposed to diclofenac.

Reactions induced by diclofenac in rainbow trout were observed to be most prominent in the kidney, liver and gills (Schwaiger et al. 2004). Our results did not confirm similar observations in the embryo-larval developmental stage of common carp. The interspecies differences in NSAIDs sensitivity are connected to the heterogeneous metabolism of individual fish species (Dolezelova et al. 2011).

The subchronic effect of ketoprofen on embryo-larval developmental stages of common carp expressed as the LOEC value was $0.003 \mathrm{mg} / \mathrm{l}$. According to our results, the environmental concentration of ketoprofen in Czech rivers could have a negative effect on the growth and developmental anomalies of embryos and larval stages of carp.

\section{Acknowledgements}

This study was supported by the Ministry of Education, Youth and Sports of Czech Republic (MSM Project No. 6215712402). The authors would like to thank to Mr. Matthew Nicholls for the English proofreading.

\section{References}

Corcoran J, Winter MJ, Tyler CR 2010: Pharmaceuticals in the aquatic environment. A critical review of the evidence for health effects in fish. Crit Rev Toxicol 40: 287-304

Dolezelova P, Macova S, Plhalova L, Pistekova V, Svobodova Z 2011: The acute toxicity of clove oil to fish Danio rerio and Poecilia reticulata. Acta Vet Brno 80: 305-308

Fent K, Weston AA, Caminada D 2006: Ecotoxicology of human pharmaceuticals. Aquat Toxicol 76: 122-159

Hallare AV, Köhler HR, Triebskorn R 2004: Developmental toxicity and stress protein responses in zebrafish embryos after exposure to diclofenac and its solvent, DMSO. Chemosphere 56: 659-666

Kocour M, Gela D, Rodina M, Linhart O 2005: Testing of performance in common carp Cyprinus carpio L. under pond husbandry conditions I: top-crossing with Northern mirror carp. Aquac Res 36: 1207-1215

Kodes V, Vejvodova J, Kollerova M 2010: Screening of pesticides in hydrosphere in Czech Republic. In: Hydrological days 2010 (In Czech). Hradec Kralove, Czech Republic, pp. 193-198

Kolpin D, Furlong ET, Meyer MT 2002: Pharmaceuticals, hormones, and other organic wastewater contaminants in U.S. streams, 1999-2000: A national reconnaissance. Environ Sci Technol 36: 1202-1211

OECD 1992: Guideline for testing of chemicals 210. Fish, early-life stage toxicity test, $18 \mathrm{p}$.

Penaz M, Prokes M, Kouril J, Hamackova J 1983: Early development of the carp, Cyprinus carpio. Acta Sci Nat Brno 17: 1-39

Praskova E, Voslarova E, Siroka Z, Macova S, Plhalova L, Bedanova I, Marsalek P, Pistekova V, Svobodova Z 2011: Comparison of acute toxicity of ketoprofen to juvenile and embryonic stages of Danio rerio. Neuroendocrinol Lett 32: 117-120

Schwaiger J, Ferling H, Mallow U, Wintermayr H, Negele RD 2004: Toxic effects of the non-steroidal antiinflammatory drug diclofenac: Part I: histopathological alterations and bioaccumulation in rainbow trout. Aquat Toxicol 68: 141-150

Thibaut R, Schnell S, Porte C 2006: The interference of pharmaceuticals with endogenous and xenobiotic metabolizing enzymes in carp liver: An in-vitro study. Environ Sci Technol 40: 5154-5160

Van den Brandhof EJ, Montforts M 2010: Fish embryo toxicity of carbamazepine, diclofenac and metoprolol. Ecotoxicol Environ Saf 73: 1862-1866

Vane JR, Botting RM 1998: Mechanism of action of antiinflammatory drugs. Int J Tissue React 20: 3-15

Zar JH 1996: Biostatistical Analysis ( $3^{\text {rd }}$ ed). Prentice-Hall, NJ, USA 